\title{
Quem tem medo de Paulo Freire e por quê?
}

Benerval Pinheiro Santos ${ }^{1}$

\section{Resumo}

Neste artigo, buscamos identificar e apresentar dados e fatos que, de algum modo, configuram os processos de perseguição e anulação de Paulo Freire e das suas contribuições teóricas e práticas pelos grupos economicamente dominantes de nosso país. Para isso, buscamos em registros, fatos históricos e documentos oficiais embasamentos que, em conjunto, mostram-nos que as reações a Freire têm origem no seio desses grupos dominantes e que fazem parte de uma estratégia de manutenção de regalias e domínios. Avançamos até a história recente, que tem o golpe político, jurídico e midiático de 2016 como um dos passos do processo de dominação desses grupos. Em termos teóricos, buscamos embasamento em referências nos campos da História e da Educação. As teorizações e contribuições de Freire são trazidas no sentido de evidenciar pontualmente o porquê as reações a ele são tão marcantes. Em nossas conclusões, retomamos os nossos objetivos e fazemos o que podemos considerar como um exercício teórico, quando apontamos um vir a ser, algumas possibilidades interrompidas em termos de uma trajetória abortada na linha de nossa história, com o golpe de estado de 2016.

\section{Palavras-chave}

Paulo Freire. Reações. Golpe de Estado. Educação.

\footnotetext{
${ }^{1}$ Doutor em Ensino de Ciências e Matemática pela Faculdade de Educação da Universidade de São Paulo, Brasil; professor associado da Faculdade de Educação da Universidade Federal de Uberlândia, Minas Gerais, Brasil. E-mail: benervalsantos@gmail.com.
} 


\title{
Who is afraid of Paulo Freire and why?
}

Benerval Pinheiro Santos ${ }^{2}$

\begin{abstract}
In this article, we seek to identify and present data and facts that, in some way, configure the processes of persecution and annulment of Paulo Freire and his theoretical and practical contributions by the economically dominant groups of our country. For this, we seek, in records, historical facts and in official documents, basis that, together, show us that the reactions to Freire originate within these dominant groups and that they are part of a strategy of maintaining their perks and domains. We move on to recent history, which has the political, legal and media coup of 2016 as one of the steps in the process of domination of these groups. In theoretical terms, we seek to base references in the fields of History and Education. Freire's theorizations and contributions are brought in the sense of showing punctually why the reactions to him are so striking. In our conclusions, we resume our objectives and do what we can consider as a theoretical exercise, when we point out a becoming, some interrupted possibilities in terms of an aborted trajectory in the line of our history, with the coup d'état of 2016.
\end{abstract}

\section{Keywords}

Paulo Freire. Reactions. Coup d'état. Education.

\footnotetext{
${ }^{2} \mathrm{PhD}$ in Science and Mathematics Teaching, Faculty of Education of the University of São Paulo, Brazil; associate professor at the Faculty of Education, Federal University of Uberlândia, Minas Gerais, Brazil. Email: benervalsantos@gmail.com.
} 


\section{Para início do diálogo}

Quando nos propusemos à tarefa de falar sobre Paulo Freire, nesse momento de comemoração do centenário do nascimento do autor, diversas possibilidades se apresentaram a nós como caminhos possíveis e, de algum modo, profícuos: poderíamos falar sobre Freire e suas contribuições para a Educação; também, em um caminho não menos interessante, talvez por conta de nossa formação em Educação Matemática, poderíamos tecer paralelos entre as teorizações do autor e a Matemática e seu processo pedagógico de ensino e aprendizagem; ainda, outra possível trajetória seria o traçar da história de vida de Freire e as constituições dos campos de investigações e práticas inauguradas por ele, como a Pedagogia Libertadora, a Educação Popular, entre outros.

Entretanto, a partir do ano de 2016, em decorrência do golpe político, jurídico e midiático sofrido não apenas pela ex-presidenta Dilma Rousseff, mas por todo o processo democrático que a elegeu, observamos o acirramento de ataques contra Paulo Freire e sua obra. Ainda, esses ataques se intensificaram com a eleição do presidente Jair Messias Bolsonaro no final de 2018.

Utilizamos o termo acirramento de ataques contra Freire porque entendemos que ele nunca deixou de ser temido e atacado pelos grupos financeiramente dominantes e por outros setores reacionários de nossa sociedade. Nesse sentido, as teorizações e contribuições práticas de Freire raramente figuraram em documentos da área da Educação e em documentos oficiais produzidos pelo $\mathrm{MEC}^{3}$.

Não nos deteremos na busca por elementos que provem a existência desse temor. Assim, partindo dessa hipótese, nos propomos a buscar e evidenciar possíveis motivos e causas para ele ${ }^{4}$.

Isso não torna a nossa tarefa menos árdua. De fato, em decorrência da construção de nossa investigação de doutoramento (SANTOS, 2007), compreendemos que as origens desse temor coincidem exatamente com o processo de nossa constituição sócio-étnico-cultural e têm raízes muito profundas na empresa colonizadora portuguesa que aportou no Brasil em 1500.

\footnotetext{
${ }^{3}$ Cabe aqui um parêntese para apresentarmos uma exceção no período que vai de 2003 a 2014, quando suas teorizações passaram a figurar e a fundamentar alguns documentos oficiais produzidos pelo MEC. Além disso, foi nesse período que Freire tornou-se patrono da Educação brasileira.

${ }^{4}$ Apenas para delimitar alguns exemplos desse temor, podemos citar a prisão e exílio de Freire após o golpe militar de 1964 e, mais recentemente, as tentativas parlamentares para retirar-lhe o título de patrono da Educação brasileira.
} 
Por isso, para compreendermos um pouco melhor essa questão e suas nuances, devemos trilhar um pouco em nossa história.

\section{Um pouco de história}

Quando falamos em "nação brasileira", devemos atentar mais amiúde ao significado desse termo. Atreladas a ele estão a ideia de participação do povo - cidadãos/ãs - nas instâncias deliberativas, com acesso aos bens culturais materiais e imateriais (museus, teatros, cinemas, músicas, escolas, universidades, instituições de dança, praias, acesso ao turismo etc.) e as condições necessárias à vida em comum (Segurança, Saúde, Educação, Transporte, Habitação etc.).

Contudo, "na verdade, um homem é cidadão de onde o reconhecem como tal" (MORAIS, 1989, p. 42). Assim, a sociedade brasileira constituiu diversos mecanismos de credenciamento e de distinção de classe que, grosso modo, tiveram e têm por objetivo, direta ou indiretamente, separar, credenciar e validar quem é ou não um/uma cidadão/ã de plenos direitos 5 .

De fato, não precisamos voltar muito à nossa história para compreendermos que os direitos fundamentais foram sempre negados à maioria da população brasileira. A título de exemplo, na década de 1960, nossa sociedade contava com um índice de 39,6\% de analfabetismo entre pessoas com mais de $15 \operatorname{anos}^{6}$. No mesmo período, apenas maiores de idade e alfabetizados/as podiam votar. Ou seja, "num país de analfabetos, a exigência de alfabetização era um obstáculo eficiente para enquadrar o eleitorado” (MALERBA, 1999, p. 148).

Ao longo de nossa história, os grupos economicamente dominantes sempre buscaram subterfúgios e ações práticas que obliterassem ou impedissem as formas de participação da maioria das pessoas nos processos eletivos. Em alguns momentos, a posse de terras era suficiente como fator impeditivo. Em outros, possuir certa soma de dinheiro bastava para eliminar a possível participação da maioria da população. De um modo geral, podemos observar que, no decorrer da história, o Brasil pode ser considerado um tipo de empresa.

\footnotetext{
${ }^{5}$ Lembro-me bem da minha adolescência vivida nas extremas periferias da capital do Estado de São Paulo, quando a polícia, com ações truculentas de averiguação (com mais vigor contra negros/as e homens LGBTQIA+), prendia quem não estivesse portando a Carteira de Trabalho com registro trabalhista. Ou seja, quem por desventura estivesse desempregado era automaticamente considerado vagabundo, bandido, meliante, drogado etc., e não merecedor de sua liberdade.

${ }^{6}$ Isso em média nacional; em diversos Estados esse índice era muito maior. 
Nessa direção, segundo Basbaum (1982, p. 278), “durante toda a vida do Império foi o Brasil o país de uma só classe: a aristocracia rural e latifundiária que votava, se elegia, legislava, executava e julgava em seu próprio proveito". Não consideramos absurda a afirmação de que essa mentalidade ainda persiste com força em nossa sociedade.

Após a Segunda Guerra Mundial, com a redemocratização de nosso país, somado ao crescente processo de industrialização, o povo ansiava por participação e acesso, principalmente, à Educação e aos processos decisórios.

Frente a esse cenário, em uma de suas primeiras obras, sua tese para o concurso à cadeira de História e Filosofia da Educação na Escola de Belas Artes de Pernambuco, defendida em 1959 na Universidade Federal do Recife - hoje, Universidade Federal de Pernambuco -, publicada postumamente com o título Educação e Realidade Brasileira (FREIRE, 2001), Freire já explicitava uma profunda compreensão da realidade brasileira, bem como apresentava estratégias teórico-práticas para a superação daquilo que chamou de "antinomia fundamental". Segundo ele,

A antinomia fundamental de que a atualidade brasileira vem se nutrindo e de que se ramificam outros termos antinômicos é a que se manifesta no jogo de dois polos de um lado, a "inexperiência democrática", formada e desenvolvida nas linhas típicas de nossa colonização e, de outro, a "emersão do povo na vida pública nacional", provocada pela industrialização do país. (FREIRE, 2001, p. 26).

De fato, ao compreender que a falta de acesso das camadas populares à Educação representava um dos elementos principais e fundantes dessa antinomia marcada por um autoritarismo antidemocrático, vertical, assistencialista, antidialógico e excludente, Freire volta suas atenções às formas de superar essa realidade, tendo a participação popular como uma das questões a ser enfrentada e superada.

A experiência de Angicos, no Rio Grande do Norte, quando 300 pessoas foram alfabetizadas em apenas 45 dias por meio de práticas desenvolvidas por Freire, chamou a atenção do então presidente João Goulart. Na figura 1, podemos observar Freire explicando seu método de alfabetização a João Goulart, Miguel Arraes e a outras autoridades.

Frente a isso, o Governo Federal adota o então chamado "método Paulo Freire de Alfabetização" ou "Pedagogia do Oprimido", como foi batizado por Freire, por meio da Campanha Nacional de Alfabetização (CNA) coordenada pela Comissão de Cultura Popular (CCP), presidida por Paulo Freire. A CNA foi lançada em 21 de janeiro de 1964. 
Figura 1 - Em pé, Paulo Freire explica ao presidente João Goulart e a políticos nordestinos a Pedagogia do Oprimido, observado por Miguel Arraes (à sua esquerda) e outras autoridades

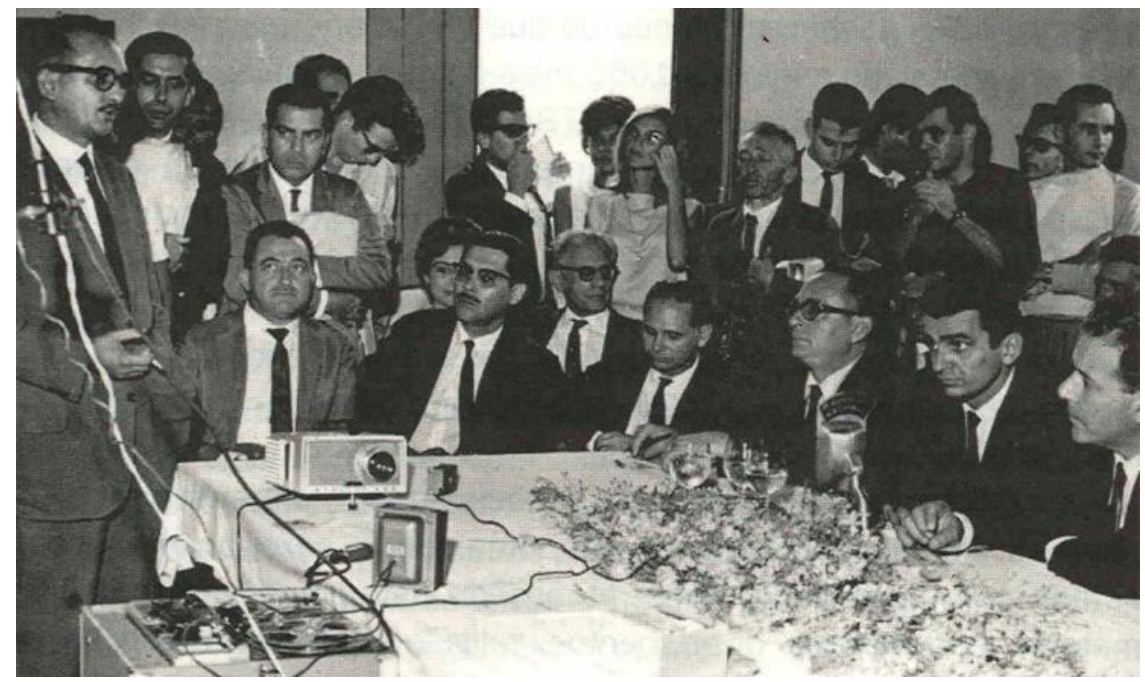

Fonte: http://memorialdademocracia.com.br/card/governo-jango-adota-metodo-paulo-freire (11/08/2021).

Segundo dados da época, organizados pelo CCP, foram identificados 20,4 milhões de brasileiros analfabetos com idades entre 15 e 45 anos. O objetivo do Governo Federal era implementar o método de Freire em todo o território nacional com uma parceria entre o Centro Popular de Cultura (CPC) e a União Nacional dos Estudantes (UNE).

O então chamado "método Paulo Freire de Alfabetização" não se propunha apenas a alfabetizar pessoas, mas inseri-las em um processo que as levasse a compreender as suas circunstâncias, os mecanismos sociais de produção de riquezas e cultura e o acesso a esses mecanismos. "O que importa, realmente, ao se ajudar o homem é 'ajudá-lo a ajudar-se'. É promovê-lo. É fazê-lo agente de sua própria recuperação. É, repitamos, pô-lo numa postura conscientemente crítica diante de seus problemas e dos problemas de sua comunidade" (FREIRE, 2001, p. 16).

Entretanto, essas ações iam de encontro exatamente aos alicerces que originavam e sustentavam as desigualdades em nosso país. Não se tratava apenas de alfabetizar pessoas, uma vez que o pensador questionava e colocava em xeque todo o sistema educacional brasileiro. Segundo Freire,

o processo educativo brasileiro vem sendo uma superposição à nossa atualidade, porque:

I - Não atende a essa transição de formas econômicas, que requer toda uma revisão do agir educativo, agora devendo endereçar-se no sentido da formação de técnicos dos vários níveis, como de mão-de-obra qualificada.

II - Não atende à necessidade imperiosa de identificar o homem brasileiro com o ritmo de democratização política e cultural, criando-lhe disposições mentais 
democráticas, com que supere nossa ostensiva "inexperiência democrática". O seu verbalismo, o seu sentido seletivo e florido são contradições e obstáculos às forças democráticas em emersão.

[...] finalmente, a revisão de nosso processo educativo não pode ser parcial porque é todo ele que está inadequado e é todo ele, em conjunto, em bloco, que a cultura em elaboração precisa. (FREIRE, 2001, p. 114).

Esses apontamentos de Freire têm, naturalmente, um forte aporte nas ideias dos intelectuais do Instituto Superior de Estudos Brasileiros (ISEB), criado em 1955 pelo governo de João Café Filho. Ali se canalizavam importantes discussões e teses acerca do nacionaldesenvolvimentismo brasileiro (ROMÃO, 2001, p. 29), mas também sobre o modo como a Educação em nosso país se constituiu, adequou e assimilou nossas contradições sociais.

Buscando configurar, talvez, um tipo de Educação necessária à nossa realidade, Freire empreende um esforço teórico em sua tese (FREIRE, 2001) no sentido de identificar, antes, tipos e níveis de consciência de nosso povo e, consequentemente, o tipo de Educação necessário para a promoção/transformação dessa consciência.

Primeiramente, em sua tese (FREIRE, 2001), e, depois, em outras produções, o autor identifica três níveis de consciência, sendo que "O primeiro estado da consciência é a intransitividade. [...] A intransitividade produz uma consciência mágica. As causas que se atribuem aos desafios escapam à crítica e se tornam superstições" (FREIRE, 1979, p. 39). Esse estado de consciência é marcado essencialmente por uma existência mais vegetativa, vital como a vida em si, a-histórica.

O segundo estágio de consciência é o da consciência transitiva, marcada por uma existência mais que apenas vegetativa, com uma maior dose de espiritualidade e historicidade. Esse é o momento em que as pessoas alargam seus horizontes de interesses. Segundo Freire (1979, p. 39),

Se uma comunidade sofre uma mudança econômica, por exemplo, a consciência se promove e se transforma em transitiva. Num primeiro momento esta consciência é ingênua. Em grande parte é mágica. Este passo é automático, mas o passo para a consciência crítica não é. Somente se dá com um processo educativo de conscientização. Este passo exige um trabalho de promoção e critização. Se não se faz este processo educativo só se intensifica o desenvolvimento industrial ou tecnológico e a consciência sofrerá um abalo e será uma consciência fanática. Este fanatismo é próprio do homem massificado. ${ }^{7}$

\footnotetext{
${ }^{7}$ Podemos facilmente encontrar elementos identificadores dessa consciência fanatizada em nossa sociedade nos dias atuais, quando pessoas acreditam na existência de mamadeiras com órgãos genitais masculinos utilizadas "supostamente" em nossas escolas; quando preferem acreditar em mentiras do que em dados científicos; quando acreditam que vermífugos combatem vírus; ou mesmo quando acreditam que nosso planeta é plano, entre diversos exemplos.
} 
Frente a essa compreensão, o método de Alfabetização de Freire se constituía como um dos elementos fundantes de um processo educativo de conscientização, com uma intencionalidade clara: promover o estado de consciência ingênua para a crítica dos/as alfabetizandos/as.

Por meio do CNA, o Governo Federal pretendia alfabetizar cerca de cinco milhões de pessoas entre 1964 e 1965. Em termos práticos, isso representaria um aumento de quase 50\% no número de eleitores que votaram nas eleições presidenciais de 1960. Naquele pleito, votaram cerca de 11,6 milhões de pessoas, sendo que Jânio Quadros foi eleito com 5.636.633 votos e, seu vice, João Goulart, com 4.547.010 votos ${ }^{8}$. Todavia, naturalmente, a estrutura de mentalidade colonial e exploradora que se nutria há mais de 4 séculos de homens e mulheres massificados, alheios às condições de sua própria condição, reagiria a estas ideias e ações.

\section{Algumas (terríveis) reações}

Os grupos economicamente dominantes não poderiam permitir abalos, por menores que fossem as bases de sustentação de seu status quo. As reações surgiram com força logo após o Comício de João Goulart na Central do Brasil, na cidade do Rio de Janeiro, em 13 de março de 1964. No evento, que reuniu cerca de 150 mil pessoas, Goulart apresentou as reformas que o governo pretendia implementar no sentido de modernizar/melhorar diversos setores, como o agrário, o bancário, o administrativo e, principalmente, o eleitoral ${ }^{9}$.

Vale lembrar que, ao final de 1964, haveria eleições presidenciais. Podemos supor que, com a implementação do método de Alfabetização de Freire, o cenário político poderia ter se transformado drasticamente ${ }^{10}$.

Logo após o comício de João Goulart, mais precisamente seis dias depois, em 19 de março de 1964, as elites empresariais e militares organizaram uma forte reação ao governo por meio da Marcha da Família com Deus pela Liberdade, como mostra a Figura 2, reunindo mais de 500 mil pessoas na Praça da República, em São Paulo.

\footnotetext{
${ }^{8}$ Naquele período, votava-se no/a candidato/a à presidente/a e no/a candidato/a à vice, separadamente, podendo eventualmente pertencerem a partidos diferentes, como foi o caso de Jânio Quadros e João Goulart.

${ }^{9}$ Fonte: http://www.zonacurva.com.br/jango-no-comicio-que-mudou-o-destino-do-pais. Acesso em: 4 ago. 2021.

${ }^{10}$ Não podemos incorrer em certa ingenuidade e acreditar que apenas as ações implementadas por Freire levaram às reações e ao golpe militar de 1964, mas é possível afirmarmos que, em grande parte, elas contribuíram para isso.
} 
Figura 2 - Marcha da Família com Deus pela Liberdade, 19 de março de 1964

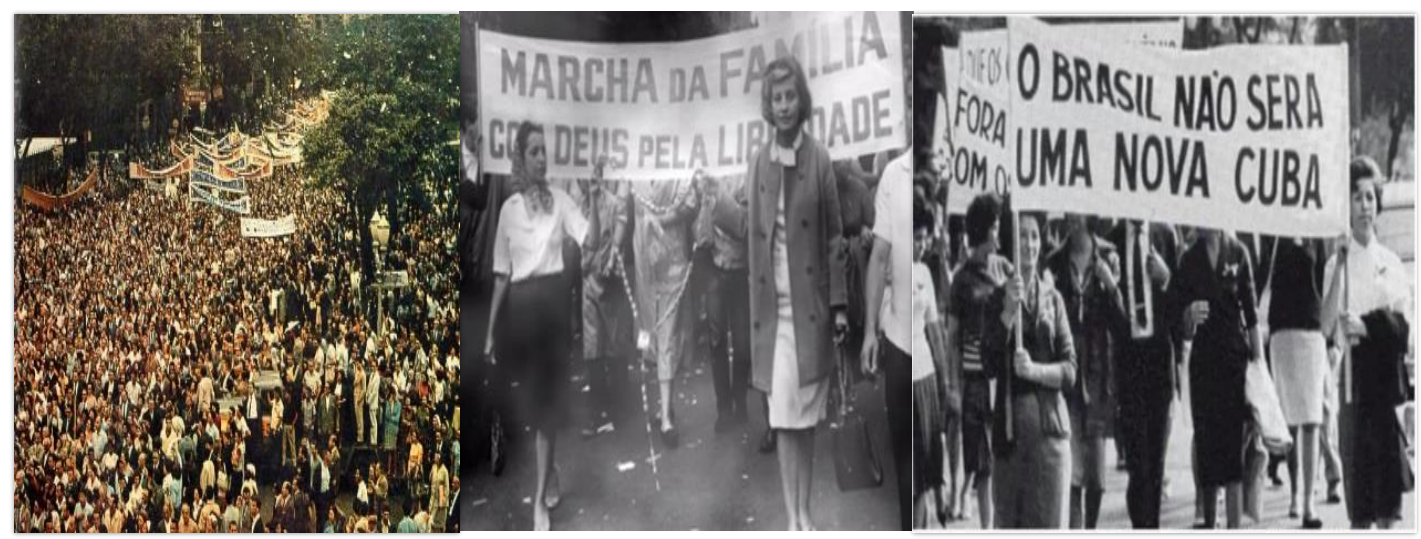

Fonte: www.uol.com.br (25/06/2021).

Para essas elites, derrubar João Goulart e criminalizar todos/as os/as envolvidos/as em qualquer tentativa ou ação que levasse à ruptura do tecido social vigente era necessário e urgente.

De fato, tudo nos leva a crer que os grupos dominantes compreenderam as possíveis consequências da implementação das ações propostas pelo governo Jango. Com apoio das elites nacionais e, agora, sabemos também que com apoio do governo estadunidense, por meio da Central Intelligence Agency (CIA), a oposição ao governo articula o Golpe de 1 de abril de 1964, menos de um mês após o comício de João Goulart.

\section{A prisão de Freire e a expansão de seus horizontes}

Com o golpe de 1964, milhares de intelectuais brasileiros de esquerda ou pessoas que, de algum modo, representavam perigo aos golpistas foram presos. Muitos/as foram torturados/as e mortos/as e outros/as conseguiram se exilar. Freire é preso sob as acusações de ser um traidor de Cristo e do povo brasileiro, além de ser considerado um subversivo internacional.

Mesmo em um Estado de Exceção, prender um educador com a trajetória e as contribuições de Freire poderia gerar reações no seio das camadas populares e médias brasileiras. Assim, lançando mão de artifícios inerentes a estados autoritários e antidemocráticos, diversas mentiras foram propagadas sobre ele. Segundo o autor,

Chegou-se a dizer que haviam encontrado, depois do Golpe de 64, na sede do movimento, quantidade enorme de uniformes de guerrilheiros, e de armas também, para a luta armada que preparávamos. Quando me foi informalmente posta esta 
questão num dos quartéis em que estive preso, não pude deixar de, com humor, rir de mim mesmo, do professor Paulo Rosas, do professor Germano Coelho, da professora Anita Paes Barreto, do escultor Abelardo da Hora, de nós todos, imaginando-nos com farda de comandante, com boné de comandante na cabeça, treinando os jovens guerrilheiros. E até gente do nosso ciclo de amizade, considerada séria e sadia, veiculou esta, mais do que inverdade, alucinação. E o fazia como bom alucinado, absolutamente certo da existência do fato, objeto de sua alucinação, de sua fantasia, de sua insensatez. (FREIRE, 2003, p. 155). ${ }^{11}$

Essas acusações se somaram a diversas outras que tiveram por objetivo destruir a credibilidade de Freire como educador/alfabetizador. Tentaram provar que ele não detinha conhecimento algum sobre alfabetização e que outros métodos de alfabetização eram superiores aos dele, além das tentativas de configurá-lo ideologicamente. "Você nega perguntava um dos juízes - que seu método é semelhante ao de Stalin, Hitler, Perón e Mussolini? Você nega que com o seu pretensioso método o que pretende é fazer o país bolchevique?” (FREIRE, 1974, p. 2 apud BEISIEGEL, 1981, p. 354-355).

Frente a esse cenário é possível concordarmos com o professor Luiz E. Aguiar quando ele diz que "demonizar Freire é parte de uma estratégia" 12 . Não se trata de combater Freire em si, mas as consequências de suas ideias e ações.

Depois de 70 dias preso, Freire é convencido por seus familiares a se exilar. Primeiramente, consegue exílio apenas na embaixada da Bolívia, tendo em vista que as demais já estavam sobrecarregadas com pedidos semelhantes. Logo em seguida, a Bolívia também sofre um golpe militar, o que obriga Freire a buscar outro exílio. Consegue abrigo no Chile. De acordo com Gadotti,

\begin{abstract}
Neste país viveu de novembro de 1964 a abril de 1969, trabalhando como assessor do Instituto de Desarollo Agropecuario e do Ministério da Educação do Chile e como consultor da UNESCO junto ao Instituto de Capacitación e Investigación em Reforma Agrária do Chile. Nessa ocasião foi convidado também para lecionar nos Estados Unidos e trabalhar no Conselho Mundial de Igrejas. Atendeu aos dois convites. (GADOTTI, 1996, p. 42).
\end{abstract}

Nosso objetivo aqui não gira em torno de configurar o que podemos chamar de estágios teóricos das ações de Freire, porém, cabe salientarmos que a compreensão das lutas de classes tanto no Brasil quanto no Chile modificou de algum modo suas ações, que se alinham agora com uma práxis revolucionária.

\footnotetext{
11 As mentiras são, a nosso ver, um dos primeiros indícios e identificadores de um Estado de Exceção. Recentemente, pudemos acompanhar as diversas mentiras propagadas contra o ex-presidente Luiz Inácio Lula da Silva, que levaram à prisão de Lula por mais de um ano e meio.

12 Fala proferida na live "Paulo Freire: educador e companheiro". Disponível em: https://www.youtube.com/watch?v=wEBDt4EZY8I". Acesso em: 4 ago. 2021.
} 
Em abril de 1969, Freire vai para os Estados Unidos da América (EUA), onde viveu até fevereiro de 1970, atuando como professor convidado da Universidade de Harvard. Após esse período, atendendo ao convite para atuar como Consultor Especial do Departamento de Educação do Conselho Mundial de Igrejas, mudou-se para a Suíça, onde atuou também na Universidade de Genebra (GADOTTI, 1996, p. 42-43; OLIVEIRA; DOMINICE, 1981, p. 67).

É emblemático um trecho da carta que Freire encaminha ao Conselho Mundial de Igrejas quando aceita o convite para atuar na Suíça. "Freire, coerente com o novo pensamento, estabelece enfaticamente: 'Vocês devem saber que tomei uma decisão: Meu problema é o problema dos esfarrapados da terra. Vocês precisam saber que optei pela revolução"” (GADOTTI, 1996, p. 163). Por meio de sua atuação no Conselho Mundial de Igrejas, Freire teve a oportunidade de atuar em diversos países africanos, sendo eles Cabo Verde, São Tomé e Príncipe, Angola, Guiné-Bissau, Zâmbia e Tanzânia.

Nesse período, diversos brasileiros exilados fundaram, juntamente com Paulo Freire, o Instituto de Ação Cultural (IDAC). Com Freire eleito presidente, "este Instituto tinha por finalidade oferecer serviços educativos, especialmente aos países do Terceiro Mundo que lutavam por sua independência” (GERHARDT, 1996, p. 163). Assim, processos de alfabetização comprometidos com libertação e lutas pela independência e contra práticas opressoras passam a ter, nas ideias de Freire, um forte embasamento teórico e prático. Freire ganha o mundo e o mundo ganha Freire.

\section{Redemocratizando e que não foi democratizado}

Durante a vigência do golpe militar brasileiro, de 1964 a 1985, nada avançamos no sentido de superarmos a nossa histórica inexperiência democrática. Ao contrário, os grupos que financiaram e deram sustentação política ao golpe muito fizeram para recrudescer práticas opressoras, esvaziadas de possibilidades de avançar para o estado de consciência crítica defendido por Freire em sua tese (FREIRE, 2001).

Em substituição ao plano de alfabetização proposto por João Goulart, os militares implementaram o Movimento Brasileiro de Alfabetização (MOBRAL). Isso aconteceu em março de 1968, quase 4 anos após o Golpe de 1964, já no governo de Costa e Silva, que a nosso ver foi um dos mais cruéis e perversos do período militar. Esse plano vigorou até a década de 1980 e pode ser considerado como uma forma de mudar para não mudar. Conseguir 
grafar o próprio nome em uma cédula eleitoral já era suficiente para considerar alguém alfabetizado $^{13}$.

Os mecanismos sociais implementados durante o regime militar que prestaram desserviços no sentido de desenvolver o estado de consciência proposto por Freire foram muitos. A Reforma Universitária de 1968 é bastante contemplativa para configurar como exemplo.

Em uma sociedade em que os sistemas educativos eram expressão das desigualdades sociais, configurando-se como mecanismos de credenciamento e de ascensão social, particularmente o Ensino Superior, é natural que os/as desfavorecidos/as vejam a Educação como uma tábua de salvação e lutem para ter acesso a ela.

Na década de 1960, mesmo que estatisticamente não houvesse uma diferença significativa em comparação à população brasileira, a quantidade de pessoas que venciam os obstáculos impostos pela Educação Básica e que chegavam às universidades por meio dos processos vestibulares geravam um grande número de excedentes, pois a oferta de vagas não avançou de modo a suprir essa nova demanda. ${ }^{14}$

A Reforma Universitária de 1968, pensada a partir do relatório Atcon ${ }^{15}$, feito por técnicos americanos, aponta como solução para o problema dos excedentes um novo modelo de acesso ao Ensino Superior: a nota de corte, modelo este em vigor ainda hoje em nossas universidades. Nesse modelo, transfere-se aos/às candidatos/as a responsabilidade pelo não acesso às universidades. Não é forçoso afirmarmos que esse modelo tornou legal a exclusão.

Além de ter a quantidade de vagas aumentada nas universidades públicas, o novo modelo de acesso levou à adequação dos currículos da Educação Básica àquilo que seria cobrado nos vestibulares. Assim, o objetivo de preparação de nossos/as jovens e crianças para

\footnotetext{
${ }^{13}$ Não nos deteremos aqui nos crimes do período militar, nem nas mazelas que marcaram nossa dívida externa, nossa Educação Básica e Superior, nem nas obras faraônicas e inúteis, pois isso demandaria um espaço maior.

${ }^{14}$ Em 1967, havia 11.600.000 alunos matriculados no nível primário, 2.700 .000 alunos matriculados no nível secundário e 214.000 alunos matriculados no nível superior. Ou seja, apenas 1,84\% dos alunos do primário se matricularam no Ensino Superior naquele ano. Contudo, essas 214.000 matrículas representam um aumento de 431\% em comparação aos 49.700 que estavam matriculados no Ensino Superior no ano de 1950. Mas, de fato, a quantidade de pessoas que passavam nos processos vestibulares era muito maior que essa quantidade de matriculados. Isso porque, até então, para passar nos vestibulares bastava ter nota superior a 5 (numa escala de 0 a 10). Isso gerava os chamados excedentes: aprovados, mas sem vagas nas universidades (TEIXEIRA, 1976, p. $315)$.

${ }^{15}$ Este relatório entrou para a história com esse nome em decorrência do sobrenome de seu idealizador. Segundo Gadotti (2000, p. 120), "Com a vinda ao Brasil, naquele mesmo ano, do professor da Universidade de Huston, Rudolph Atcon, inaugura-se um novo estilo na política educacional no país. Como o Sr. Roberto Campos, Ministro da Fazenda, entregará a elaboração do orçamento nacional a técnicos americanos, o Ministro da Educação entregará a reformulação da política educacional brasileira a técnicos".
} 
a vida na Educação Básica cai por terra, tornando este ramo de ensino uma mera preparação, ou simulacro disso, ao Ensino Superior.

Dito de outro modo, a Reforma de 1968, além de não apresentar solução aos problemas e processos excludentes relacionados ao Ensino Superior, generaliza e aumenta os mecanismos de exclusão já existentes. Em primeiro lugar, porque, como mencionamos na nota 12 , menos de $2 \%$ dos ingressantes no primário chegavam ao Ensino Superior. Soma-se a isso a proliferação de cursinhos preparatórios para os exames vestibulares tornando-se algo quase obrigatório para quem almejava (e, ainda hoje, almeja) uma vaga em universidades públicas. Isso em si já excluía a maioria da população brasileira que não tinha (e, ainda hoje, não tem) condições financeiras para pagar por esses serviços. Em segundo lugar, porque propiciou a proliferação do Ensino Superior privado, que também excluía (e, ainda hoje, exclui) a maioria da população brasileira ${ }^{16}$.

Mais recentemente, após 2003, com a eleição do ex-presidente Lula, a questão da expansão do Ensino Superior público foi retomada como uma política principal de seu governo, por meio do programa Reestruturação e Expansão das Universidades Federais (Reuni). A Figura 3 apresenta em gráfico o aumento na quantidade de Universidades Federais entre 2003 e 2010. Nesse período, foram criadas 14 universidades, aumento este atrelado também a um processo de interiorização do Ensino Superior público federal.

Figura 3 - Aumento do número de universidades federais entre 2003 e 2010

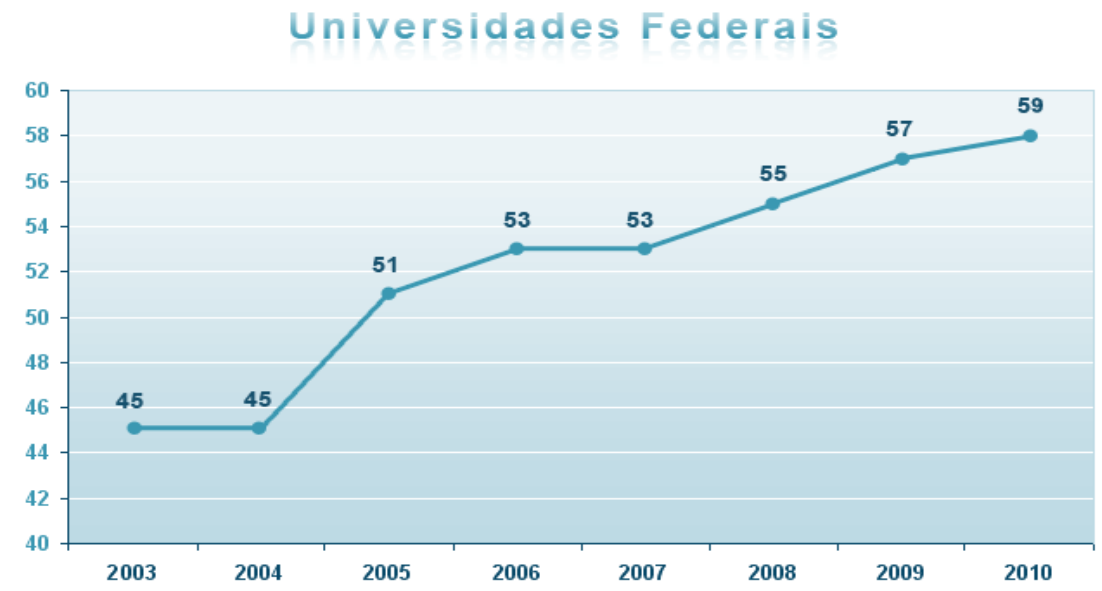

Fonte: http://reuni.mec.gov.br/expansao (08/08/2021).

\footnotetext{
${ }^{16}$ Tendo por base o relatório Censo do Ensino Superior do ano de 2003, feito pelo Ministério da Educação, observamos que, das 1.859 Instituições de Ensino Superior, as públicas somam 207, isto é, 11,1\%, e as particulares somam 1.652, ou seja, 88,9\% . Ainda, das 207 IES públicas, 83 (4,5\% do total) são federais, 65 (3,5\% do total) são estaduais e 59 (3,2\% do total) são municipais. Essas quantidades, quando relacionadas às dimensões de população de nosso território, tornam-se ridículas. 
Com o Reuni, as universidades federais dobraram a oferta de vagas. Eram 109,2 mil em 2003 e chegaram a 222,4 mil este ano [2010]. Para atender o novo contingente de alunos, as instituições contrataram professores e técnicos administrativos. Com isso, o conjunto das instituições de educação superior, que contava com 40.823 professores em 2003, tem agora 63.112. O número de técnicos administrativos subiu de 85 mil para $105 \mathrm{mil}^{17}$.

Na mesma direção, as escolas técnicas federais, com a adoção da política de extensão, tiveram seu aumento quantitativo para 342 unidades. Vale lembrar que, entre 1909 e 2002, apenas 140 escolas técnicas federais haviam sido criadas.

O quantitativo de vagas e de novas universidades públicas federais em nosso país é inegável. Isso fica evidenciado no gráfico apresentado na Figura 4, considerando o período que vai de 1980 a 2017.

Figura 4 - Número de matriculados em cursos de graduação, entre 1980 e 2017

Número de Matrículas em Cursos de Graduação, por Categoria Administrativa - 1980-201 7

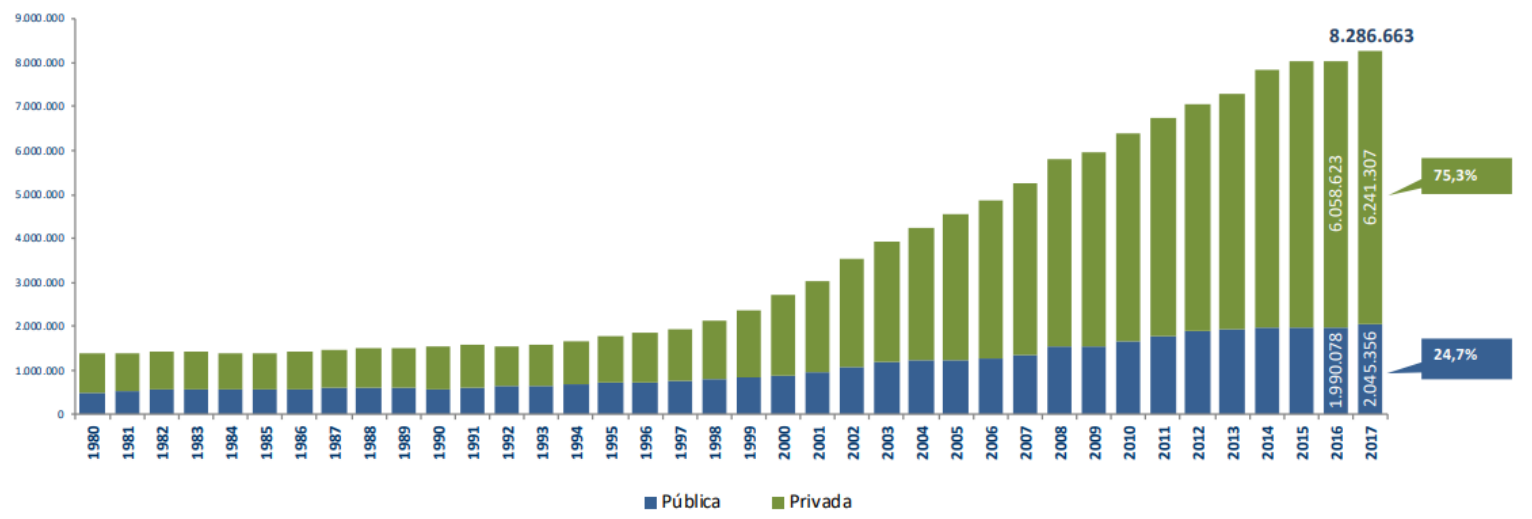

Fonte: www.portal.mec.gov.br/index (08/08/2021).

Entretanto, o gráfico acima nos mostra que o quantitativo de matriculados em universidades privadas também aumentou significativamente no mesmo período, sobrepondose à quantidade de matriculados nas universidades públicas federais. Dito de outro modo, as elites economicamente dominantes, tudo nos leva a crer, até permitiram a expansão da rede federal, mas a contrapartida é evidente a seu favor.

Outra questão a ser considerada diz respeito ao que podemos chamar de cultura do Ensino Superior, isto é, expandiu-se o mesmo modelo de universidade, sem que se questionasse os seus objetivos e a relação entre universidade e sociedade. Assim, aquilo que

17 Fonte: http://reuni.mec.gov.br/noticias/37-noticia-destaque/684-lula-destaca-politica-de-interiorizacao-doensino-superior-e-profissional. Acesso em: 8 ago. 2021. 
Freire chamou a atenção e criticou já no início da década de 1960 quando apontou que a revisão de nosso processo educativo não poderia ser parcial, sem considerar a sua inadequação à nossa cultura (ainda hoje) em transição (FREIRE, 2001), não foi contemplado no processo de expansão.

Da mesma forma, não se repensou a nossa Educação Básica nesse processo de expansão, que continua como uma (pré) preparação para o ingresso no Ensino Superior, com objetos de ensino (conteúdos) arcaicos que não contemplam a nossa diversidade étnicocultural. Ou, como enfatiza D’Ambrosio em diversas obras (1991, 1993, 1997, 1998, 1999, 2001, 2006), referindo-se aos conteúdos do ensino de Matemática na Educação Básica, são conteúdos que "DOI", porque são, sob vários aspectos, "desinteressantes", “obsoletos" e, a maioria, "inúteis" quando se pensa na formação de pessoas conscientes e críticas frente aos problemas sociais.

Mesmo não abalando as bases daquilo que podemos chamar de cultura educacional brasileira, a expansão das universidades federais somada a outras políticas, como as de cotas raciais, a de cotas para egressos de escolas públicas ao Ensino Superior público federal e a de programas como o Programa Ciência sem Fronteiras, propiciou que milhares de estudantes brasileiros/as das camadas populares não só ingressassem no Ensino Superior como fizessem intercâmbio em universidades estrangeiras, com bolsas de estudos pagas pelo governo por meio de suas agências de fomento, como a Coordenação de Aperfeiçoamento de Pessoal de Nível Superior (CAPES) e o Conselho Nacional de Desenvolvimento Científico e Tecnológico (CNPq). O Programa foi criado em julho de 2011, pela então presidenta Dilma Rousseff, para

promover a consolidação, expansão e internacionalização da ciência e da tecnologia, da inovação e da competitividade brasileira por meio do intercâmbio de estudantes de graduação e de pós-graduação e da mobilidade internacional. $\mathrm{O}$ programa prevê a concessão de mais de 100 mil bolsas de estudos no exterior em quatro anos. ${ }^{18}$

Foi inegável a importância desse programa no sentido de propiciar que jovens brasileiros/as das camadas populares tivessem acesso a outras culturas em dezenas de países. Somam-se a isso diversos outros programas sociais implementados ao longo dos governos de Lula e Dilma, que possibilitaram tirar o Brasil do Mapa Mundial da Fome em 2014. ${ }^{19}$ “'De

\footnotetext{
${ }^{18}$ Fonte: www.portal.mec.gov.br/component/tags/tag/35172. Acesso em: 8 ago. 2021.

${ }^{19}$ Entretanto, apenas dois anos após o golpe de 2016, em 2018, o Brasil retorna ao mapa da fome.
} 
2002 a 2013, caiu em 82\% a população de brasileiros considerados em situação de subalimentação". ${ }^{20}$

Mesmo representando pequenos avanços no sentido de diminuir a enorme distância econômica entre ricos e pobres em nosso país, esses programas e políticas incomodaram as elites economicamente dominantes. Para agravar esse cenário, o Brasil, por meio da Petrobrás, descobriu o Pré-Sal em 2006. Isso representou uma real possibilidade de tornar o Brasil autossuficiente no consumo do petróleo e seus derivados.

\section{No meio do caminho havia um Pré-Sal... e um Golpe de Estado}

Com a descoberta do Pré-Sal, o Brasil passa a figurar entre os 5 maiores detentores de reservas de petróleo do mundo. Em 2013, durante o governo da ex-presidenta Dilma Rousseff, foi aprovado um projeto de lei que destinaria $75 \%$ dos royalties do petróleo para a Educação, e 25\% para a Saúde. Isso representaria um aporte de bilhões de reais a mais para essas áreas, porém, era algo que as elites economicamente dominantes, aliadas aos EUA, não poderiam permitir.

Esse cenário é muito mais complexo do que o apresentado aqui e envolve diversas questões, como a criação do BRICS, formado por Brasil, Rússia, Índia, China e África do Sul, que abalaria as relações econômicas e, de algum modo, políticas, entre o Brasil e os EUA.

O fato é que a descoberta do Pré-Sal sob um governo que podemos considerar como de centro-esquerda abalaria as relações econômicas internas e externas do Brasil. Não temos como medir as consequências sociais que essa descoberta e o consequente aporte financeiro em áreas que beneficiariam milhões de pessoas das camadas populares gerariam, mas não consideramos absurdo afirmarmos que o cenário social em nosso país se modificaria para melhor.

Em um processo com motivações diferentes, mas gerido e organizado pelos mesmos grupos econômicos que derrubaram João Goulart e levaram ao golpe de 1964 - as tradicionais elites econômicas, os empresários, os membros de determinados grupos das igrejas evangélicas, alguns setores militares e os membros do poder judiciário vinculados à Operação Lava-Jato - foi arquitetada a derrubada da ex-presidenta Dilma Rousseff e uma brutal tentativa de criminalizar o Partido dos Trabalhadores (PT), como mostram bandeiras e faixas presentes nas manifestações pró-impeachment, na Figura 5.

${ }^{20}$ Fonte: www.gov.br/casacivil/pt-br/assuntos/noticias/2014/setembro/relatorio-indica-que-brasil-saiu-do-mapamundial-da-fome-em-2014. Acesso em: 8 ago. 2021. 
Figura 5 - Manifestações pró-impeachment da Presidenta Dilma Rousseff na Avenida Paulista em São Paulo, em 2016

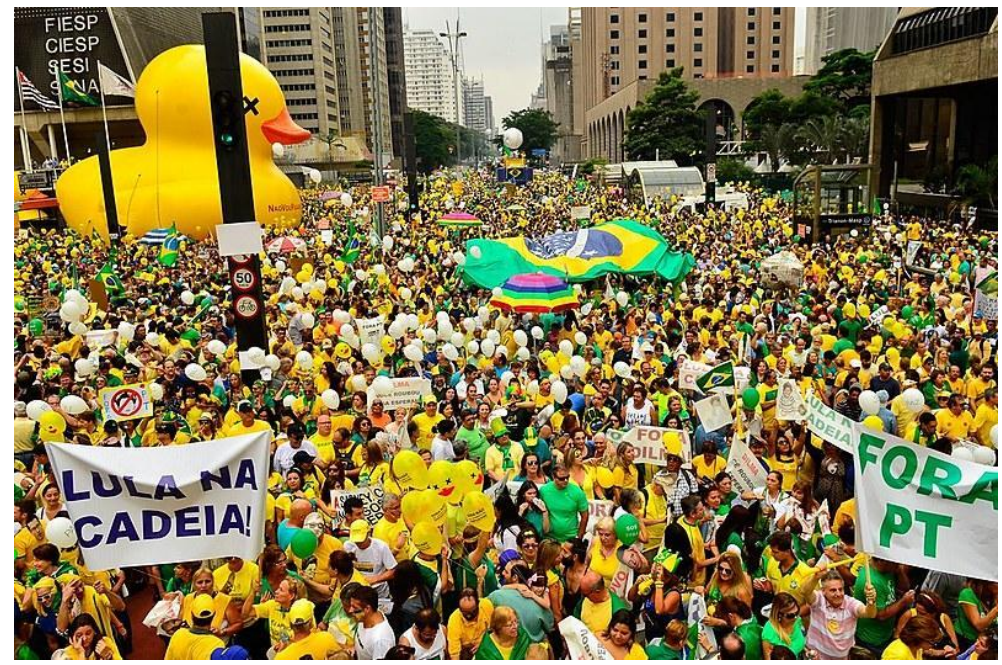

Fonte: www.brasildefato.com.br (22/06/2021).

O golpe político, jurídico e midiático de 2016 representou um grande retrocesso nos avanços sociais que o Brasil estava construindo e experienciando. Com ele, quase todos os programas sociais implementados até então pelos governos Lula e Dilma foram eliminados ou esvaziados de recursos. Houve, também, a entrega do Pré-Sal ao capital internacional, por meio de sua privatização, já no primeiro mês do governo golpista de Michel Temer, em 2016.

O programa Ciência sem Fronteiras foi finalizado; os investimentos em pesquisas reduzidos a valores ínfimos; foram aprovadas a Reforma da Previdência (EC-95), a Emenda Constitucional 95 (EC-95), que congelou investimentos em Saúde e Educação por 20 anos, e, também, e também a Reforma Trabalhista, que pôs fim a quase todos os direitos trabalhistas garantidos pela Consolidação das Leis de Trabalho (CLT). Esses são apenas alguns exemplos dos ataques contra o povo brasileiro pós-golpe de 2016.

Com a possibilidade de Lula retornar ao governo nas eleições de 2018, tendo em vista que liderava todas as pesquisas, o mesmo grupo golpista, com o apoio da CIA, foi arquiteto no seio da Operação Lava-Jato com a criminalização e a prisão de Lula, que passou mais de um ano e meio preso, condenado apenas em segunda instância com acusações que posteriormente foram consideradas falsas. Nos dias de hoje, Lula foi inocentado de todas as acusações e tem resguardados seus direitos políticos.

O fato é que o grupo dominante que desde sempre geriu esse país não poderia permitir avanços nas áreas sociais, com uma consequente ascensão financeira e cultural das camadas populares. A distância entre senzala e casa grande não poderia ser diminuída e muito menos 
seus habitantes poderiam coexistir/conviver/coabitar nos mesmos ambientes: aeroportos, restaurantes e, principalmente, nas universidades públicas, que sempre foram um nicho preservado e destinado a atender os/as filhos/as dos grupos dominantes.

O racismo, o machismo, a LGBTfobia etc., que sempre existiram no seio de nossa sociedade, passaram a ser exacerbados, inclusive em falas e ações do então candidato à presidência Jair Messias Bolsonaro.

O Brasil retrocede. Um exemplo grotesco desse retrocesso pode ser observado, por exemplo, no indicador da felicidade do povo brasileiro entre 2019 e 2020 . Entre 2019 e 2020, enquanto este indicador diminuiu entre as camadas mais pobres, entre os $20 \%$ mais ricos, ele aumentou de 6,8 para $6,9^{21}$.

\section{Finalizando e recomeçando}

Retomando nosso objetivo, que se relaciona à busca por evidências dos possíveis motivos e causas do temor contra Freire, frente ao que apresentamos, depreendemos que:

a) o temor à Freire se relaciona ao que suas ideias e ações representam no sentido de empoderar as camadas populares;

b) com uma possível continuidade de governos de centro-esquerda, avaliamos que seria natural, em um futuro próximo, repensarmos o tipo de Educação que temos em nosso país, com forte aporte na Pedagogia Libertadora de Freire;

c) com o aporte financeiro que seria injetado nas áreas de Educação e Saúde, por meio do Pré-Sal, teríamos condições de universalizar o acesso às escolas a toda a população brasileira, além da continuação do processo de expansão do ensino público e programas de inclusão social, com uma consequente diminuição do ensino privado;

d) o avanço ao estágio de consciência crítica, defendido por Freire, seria uma consequência nesse processo.

Finalmente, Freire é temido porque as ideias e ações dele possibilitam a construção de um mundo mais humano, no qual todos e todas se somam na busca pela superação de toda e qualquer forma de exclusão, de desigualdade e de sobreposição de alguns sobre muitos/as. Um mundo no qual a Educação é uma expressão da liberdade e não da opressão. Tudo isso assusta e amedronta os grupos que, ao longo de nossa história, veem e consideram nosso país,

${ }^{21}$ Fonte: Felicidade do brasileiro cai em meio a pandemia | Agência Brasil (www.ebc.com.br). Acesso em 22 jun. 2021. 
nossas riquezas e mesmo as camadas populares como uma extensão de seus domínios e posses. Viva Freire!

\section{Referências}

BASBAUM, L. História sincera da República: das origens até 1889. 4. ed. São Paulo: AlfaÔmega, 1982.

BEISIEGEL, C. R. Política e educação popular no Brasil: um estudo sobre o método Paulo Freire de alfabetização de adultos. Tese (Livre Docência) - Faculdade de Educação, Universidade de São Paulo, São Paulo, 1981.

D’AMBROSIO, U. Matemática, ensino e educação: uma proposta global. Temas e Debates, Rio Claro, v. 1, n. 3, p. 1-16, 1991. Disponível em: http://sbem.iuri0094.hospedagemdesites.ws/revista/index.php/td/article/view/2602. Acesso em: 10 jun. 2021.

D’AMBROSIO, U. Etnomatemática: arte ou técnica de explicar e conhecer. 2. ed. São Paulo: Atual, 1993.

D’AMBROSIO, U. Transdisciplinaridade. São Paulo: Palas Athena, 1997.

D’AMBROSIO, U. Educação matemática: da teoria à prática. 4. ed. Campinas: Papirus, 1998.

D’AMBROSIO, U. Educação para uma sociedade em transição. Campinas: Papirus, 1999.

D’AMBROSIO, U. Conteúdo nos cursos de formação de professores de matemática. Etnomatemática, São Paulo, 2006. Disponível em: http://web.archive.org/web/20081209112502/http://vello.sites.uol.com.br/conteudo.htm.

Acesso em: 8 ago. 2021.

D'AMBROSIO, U. The name ethnomathematics: my personal view. Etnomatemática, São Paulo, 2006. Disponível em: https://sites.google.com/site/etnomath/11. Acesso em: 8 ago. 2021.

FREIRE, P. Educação e mudança. 2. ed. Tradução de Moacir Gadotti e Lilian Lopes Martin. Rio de Janeiro: Paz e Terra, 1979.

FREIRE, P. Educação e atualidade brasileira. São Paulo: Cortez, 2001.

FREIRE, P. Cartas a Cristina: reflexão sobre minha vida e minha práxis. 2. ed. São Paulo: UNESP, 2003.

GADOTTI, M. A voz do biógrafo brasileiro: a prática à altura do sonho. In: GADOTTI, M. (org.). Paulo Freire: uma biobibliografia. São Paulo: Cortez, 1996. p. 69-116.

GADOTTI, M. Concepção dialética da educação: um estudo introdutório. 11. ed. São Paulo: Cortez, 2000. 
GERHARDT, H. P. Uma voz europeia: arqueologia de um pensamento. In: GADOTTI, M. (org.). Paulo Freire: uma biobibliografia. São Paulo: Cortez, 1996. p. 149-170.

MALERBA, J. O Brasil Imperial (1808-1889): panorama da História do Brasil no Século XIX. Maringá: UEM, 1999.

MORAIS, R. Cultura brasileira e educação. Campinas: Papirus, 1989.

OLIVEIRA, D.; DOMINICE, P. Freire: desvelar. In: TORRES, C. A. (org.). Leitura crítica de Paulo Freire. Tradução de Mônica Mattar Oliva. São Paulo: Edições Loyola, 1981. p. 6371 .

ROMÃO, J. E. Contextualização: Paulo Freire e o pacto populista. In: FREIRE, P. Educação e atualidade brasileira. São Paulo: Cortez, 2001, p. 13-48.

SANTOS, B. P. Paulo Freire e Ubiratan D'Ambrosio: contribuições para a formação do professor de matemática no Brasil. Tese (Doutorado em Educação) - Faculdade de Educação, Universidade de São Paulo, São Paulo, 2007.

TEIXEIRA, A. Educação no Brasil. 2. ed. São Paulo: Nacional, 1976. 